\title{
Exame Nacional de Desempenho de Estudantes (ENADE) - Análise do Perfil das mulheres dos cursos da área de computação
}

\author{
Bárbara Santos Freitas $^{1}$, Luciana Balieiro Cosme ${ }^{1}$, Mayara Assis Nascimento ${ }^{1}$ \\ ${ }^{1}$ Instituto Federal do Norte de Minas Gerais - IFNMG Montes Claros \\ R. Dois, 300 - Vilage do Lago I - Montes Claros/MG - 39404-058 \\ \{barbarasfreitas1, mayaraassisn\}@gmail.com, luciana.balieiro@ifnmg.edu.br
}

\begin{abstract}
The objective of this work is to outline the profile of women in the computing field through the analysis of the database of the National Examination of Student Performance (ENADE) for the year 2017. The motivation for this work is the desire to understand and identify the factors that may show the differences between men and women in the computing study field. All the results reached by this study, the most significant one was that the main motivation for the women to enroll in a computing field course was the insertion in the labor market whilst the men declared to have a vocation for the field.
\end{abstract}

Resumo. O objetivo deste trabalho é traçar o perfil das mulheres da área de computação através de uma análise dos microdados referentes ao Exame $\mathrm{Na}$ cional de Desempenho dos Estudantes (ENADE) durante o ano de 2017. Este trabalho foi motivado pelo desejo de compreender e identificar fatores que podem mostrar as diferenças entre e homens e mulheres na área de computação. Dos resultados obtidos, o mais significativo refere-se à motivação para iniciar o curso, a maioria das mulheres foi motivada pelo desejo de inserção no mercado de trabalho enquanto os homens assumem ter uma vocação para a área.

\section{Introdução}

Os cursos da área de computação apresentam, sabidamente e amplamente divulgado, uma quantidade de homens muito superior à quantidade de mulheres. Entender melhor alguns aspectos que podem favorecer a percepção dos motivos pelos quais isso acontece, é de grande importância para criar ações e políticas que possam inserir mais mulheres na área, bem como promover uma justiça e igualdade de oportunidades. Assim, o foco deste trabalho é identificar os fatores que contribuem para este cenário e reforçar a necessidade de desmistificar a relação ao gênero associada à escolha do curso.

A participação feminina nos cursos da área de ciência e tecnologia é amplamente estudada e discutida [Oliveira et al. 2014]. Historicamente, a ciência se caracterizou como uma atividade notavelmente masculina e a participação das mulheres ocorreu aos poucos nesse processo [Moreira et al. 2014]. Além disso, mesmo quando uma mulher ou um grupo de mulheres tiveram uma importância substancial na história científica, ao se registrarem os fatos houve uma invisibilização da sua participação [Oliveira et al. 2014].

A contribuição feminina em ciência e tecnologia tem sido negligenciada, sugerindo assim que estereótipos vêm retendo a entrada de mulheres na área [Maia 2016]. Há 
também um fenômeno social chamado de Efeito Matilda, que descreve situações em que o trabalho de uma mulher é atribuído a um homem. O termo foi cunhado em 1993 pela pesquisadora da história da ciência Margaret W. Rossiter [Rossiter 1993]. Um exemplo deste fenômeno pode ser observado na história da biofísica britânica Rosalind Franklin, suas pesquisas e descobertas foram fundamentais para a compreensão da estrutura do ácido desoxirribonucleico (DNA, na sigla em inglês). A descoberta da estrutura do DNA rendeu a James Watson, Francis Crick e Maurice Wilkins o prêmio Nobel em 1962. Watson admitiu em seu livro The Double Helix ter usado os dados e as fotografias não publicadas de Rosalind sem o seu conhecimento [Rezende 2009].

Como salientou Castro (2013), um fator desestimulante de interesse das mulheres pelo setor de computação faz alusão ao vínculo construído socialmente entre tecnologia e masculinidade. Isso ocorre, de acordo com o estudo realizado pela mesma autora, porque desde criança foram influenciadas a gostar de outros assuntos, mais aceitáveis ao papel de gênero que foi socialmente construído para as mulheres, como tarefas que envolvam cuidado e comunicação. Mesmo quando escolhem uma profissão associada ao universo masculino, existe uma pressão dos amigos, colegas e da sociedade [Castro 2013].

Dada a perspectiva da existência de poucas mulheres na área de computação, o trabalho consiste em uma análise descritiva dos microdados mais recentes referentes ao Exame Nacional de Desempenho dos Estudantes (ENADE) do ano de 2017. Alguns dados dos discentes da área de computação foram observados com o objetivo de compreender e identificar fatores que podem ser fomentadores deste cenário. O resultado mais significativo refere-se à motivação para a escolha do curso, enquanto as mulheres atribuem essa escolha ao desejo de inserção no mercado de trabalho os homens assumem ter vocação para a área.

\section{Metodologia}

Os dados analisados no trabalho foram extraídos da base de microdados do portal do Instituto Nacional de Estudos e Pesquisas Educacionais Anísio Teixeira (INEP). Dentre os microdados disponibilizados pelo portal estão os do Exame Nacional de Desempenho de Estudantes (ENADE) que constituem o objeto de pesquisa deste trabalho. "O ENADE avalia o rendimento dos concluintes dos cursos de graduação, em relação aos conteúdos programáticos, habilidades e competências adquiridas em sua formação" [INEP 2015]. O exame tem caráter obrigatório, ocorre trienalmente para cada área do conhecimento e a situação de regularidade do estudante no ENADE deve constar em seu histórico escolar.

O algoritmo desenvolvido consiste numa análise estatística descritiva dos dados e a linguagem de programação utilizada para desenvolvimento do trabalho foi o Python $3^{1}$. O Python, assim como as bibliotecas utilizadas para analisar os dados foram instaladas a partir da distribuição Anaconda, gratuita e de código aberto ${ }^{2}$. Os cursos analisados foram: ciência da computação bacharel e licenciatura, tecnologia em análise e desenvolvimento de sistemas, tecnologia em redes de computadores, tecnologia em gestão da tecnologia da informação, engenharia da computação e sistemas de informação. A primeira análise foi feita dividindo, em cada um desses cursos, os estudantes do sexo masculino e feminino obtendo a quantidade dos mesmos para cada curso.

\footnotetext{
${ }^{1}$ https://www.python.org/download/releases/3.0/

${ }^{2}$ https://conda.io/en/latest/
} 
No decorrer da análise de dados do ENADE, os cursos da área de computação foram avaliados de forma conjunta. Posteriormente, os estudantes dessa grande área foram separados em duas categorias: estudantes do sexo feminino e estudantes do sexo masculino. Dessa forma, observou-se a quantidade de discentes de cada sexo nos cursos de computação de forma geral e separada por região. Além disso, aspectos de cunho socioeconômico foram observados. Questões relacionadas com cor ou raça, escolarização da mãe, dificuldades enfrentadas durante o curso, motivo para escolhê-lo, onde e com quem mora, por fim, em que tipo de escola cursou o ensino médio e o tipo de Instituição de Ensino Superior.

Para traçar um paralelo, alguns dados presentes no artigo Educação Superior em Computação Estatísticas - 2017, divulgado pela Sociedade Brasileira de Computação, foram considerados. As estatísticas deste trabalho foram construídas a partir de uma base de dados também fornecida pelo INEP, filtradas do CENSO 2017, e mostram a série histórica do estado quantitativo da Educação Superior em Computação no País [Nunes 2017].

\section{Resultados e Discussão}

Analisando os dados do ENADE do ano de 2017, foi possível confirmar a diferença entre a quantidade de discentes do sexo feminino e masculino nos cursos de computação. Em todos os cursos selecionados, o número de mulheres foi menor. A partir de uma perspectiva geral, considerando todos os cursos como uma grande área, a diferença é ainda mais evidente. De acordo com a análise, $85.4 \%$ dos 40.162 respondentes do Exame são do sexo masculino e apenas $14.6 \%$ do sexo feminino. Nessa perspectiva, pode-se fazer um paralelo com dados presentes no estudo Educação Superior em Computação Estatísticas - 2017, divulgado pela Sociedade Brasileira de Computação [Nunes 2017]. Observa-se nesse estudo a evolução do número de concluintes dos cursos de computação entre os anos de 2001 e 2017, e através dele é possível notar a disparidade existente ao longo dos dezesseis anos analisados. Ademais, é possível perceber que o número de concluintes aumenta, enquanto o número de mulheres aumenta muito pouco.

Os cursos foram agrupados em uma única variável, representando todos os homens e mulheres pertencentes aos cursos da área de computação, em seguida, duas novas variáveis foram criadas, para representar homens e mulheres, respectivamente. Foi feita a análise da quantidade de homens e mulheres por região; observando-se que a quantidade de discentes de ambos os sexos na região Sudeste é muito maior em relação às outras, ainda em relação ao Sudeste, as mulheres correspondem à $15.79 \%$ do total de discentes daquela região. No entanto, o índice de diferença mais acentuado se encontra na região Sul, na qual apenas $11 \%$ dos discentes são mulheres e o menos acentuado se encontra na região Norte em que $18.76 \%$ dos discentes são mulheres.

Os dados relacionados a cor ou raça nos mostram que mulheres e homens brancos são maioria nos cursos da área de computação analisados, 52,89\% das mulheres e 56,93\% dos homens se declararam brancos(as). Notou-se que $9,15 \%$ das mulheres e $7,71 \%$ dos homens se declararam pretos(as). Nas categorias de pessoas brancas e indígenas, a porcentagem de homens foi maior. Todavia, a porcentagem das mulheres que se afirmaram pretas, pardas e amarelas supera a porcentagem dos homens que fizeram essa afirmação.

Foi observado também o tipo de escola em que o discente cursou seu ensino médio. A maioria das mulheres e dos homens cursaram todo o ensino médio em es- 
cola pública, $68,5 \%$ das mulheres e $63,27 \%$ dos homens estudaram nesse tipo de escola. Já os que fizeram todo o ensino médio em escola particular correspondem a 24,22\% das mulheres e 26,74\% dos homens. Já para Instituição de Ensino Superior (IES), o número de pessoas cursando computação em IES privadas é superior às públicas, a análise mostra que $64.3 \%$ dos discentes estão em Instituições privadas, enquanto $35.6 \%$ pertencem às públicas. Observa-se também que a proporção de mulheres em Instituições públicas é maior, 42,96\% delas estudam em IES públicas e 34,41\% dos homens estudam em IES públicas. Considerando as IES privadas, a porcentagem dos homens e das mulheres que estudam nesse tipo é, respectivamente, $65,58 \%$ e $57,03 \%$.

Os principais motivos que levaram os discentes a escolher o curso também foram analisados e os resultados estão apresentados na Figura 1.

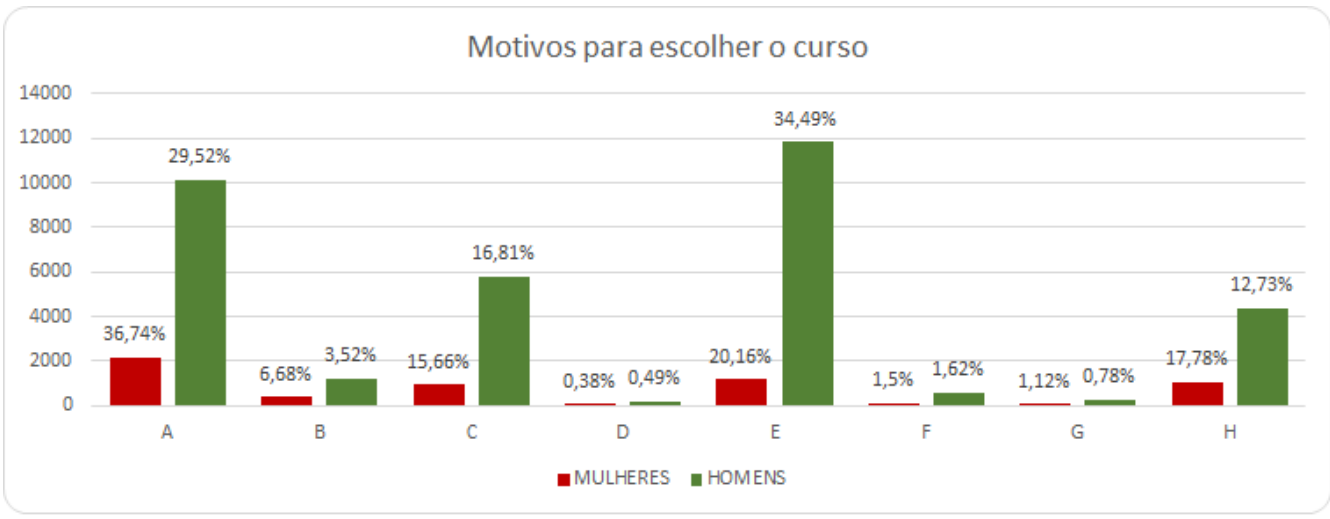

Figura 1. Motivos para escolher o curso

Os resultados mostram que, $36.74 \%$ das mulheres escolheram o curso pensando na inserção no mercado de trabalho. Já para os homens, o principal motivo para escolha do curso foi vocação, $34.49 \%$ deles escolheram essa afirmativa. Os motivos que tiveram mais representatividade de mulheres além desse já citado e a porcentagem delas que fizeram essa escolha foram, respectivamente: vocação, outro motivo e valorização profissional, $20.16 \%, 17.78 \%$ e $15.66 \%$. Para os homens, inserção no mercado de trabalho representa a segunda maior escolha, com $29.52 \%$ deles. Valorização profissional e outro motivo correspondem, respectivamente, à $16.81 \%$ e $12.73 \%$ do total de respondentes masculinos.

Nesse contexto, em que a opção mais escolhida pelos homens diz respeito à vocação, os papéis sociais que são atribuídos a mulheres e homens são confirmados. Em cossonância com Souza et. al. (2010), desde cedo ensina-se as mulheres maneiras apropriadas de se portar, quando devem falar, a serem disciplinadas, cuidar do corpo, entre outras. Ainda, de acordo com Souza et. al. (2010, p. 133), essa "natureza feminina" produz as práticas das mulheres que se responsabilizam pelo cuidado dos filhos e da casa, "que veem suas possibilidades de atuação profissional e de gozo de direito civis cerceadas por uma série de impedimentos explícitos ou camuflados". Entretanto, segundo as autoras, aos homens se reserva outro conjunto de práticas nas quais seu destemor e sua "capacidade" são louvadas e consideradas propiciadoras de um bom desempenho em matemática. E, assim, relações desiguais de gênero e exatas vão sendo concebidas. Para aumentar as mulheres nos cursos, diante desse cenário, uma proposta ainda válida é a divulgação e a desmistificação do discurso de gênero. 


\section{Conclusão}

Diante da disparidade quantitativa de mulheres e homens nos cursos da área de computação, surgiu a proposta deste trabalho que é analisar o perfil das mulheres que cursaram computação, através da uma análise exploratória estatística dos microdados referentes ao Exame Nacional de Desempenho dos Estudantes(ENADE) durante o ano de 2017. Ao final da análise os resultados observados são que a maioria das mulheres são brancas, estão no sudeste, possuem uma renda familiar entre 1 e 4 salários mínimos. Tais resultados sugerem que são mulheres com certos privilégios, assim como os homens que apresentaram os mesmos resultados. Em relação aos aspectos emocionais, observa-se que o principal apoio que as mulheres receberam para enfrentar dificuldades veio dos pais, novamente, os homens apresentaram os mesmos resultados.Por fim, a maioria das mulheres afirmou que o principal motivo para escolher o curso foi a inserção no mercado de trabalho, no entanto, a maioria dos homens afirmou que o principal motivo para escolher o curso foi a vocação. O resultado desta última questão reforça a importância de discutir o estigma amplamente propagado de que mulheres não têm vocação para a área de exatas e tecnologia. Com isso, esta é uma questão que pode ser melhor explorada e contextualizada em trabalhos futuros, abordando historicamente a fim de compreender o porquê dessa crença e se de fato há um impacto no comportamento das mulheres.

\section{Referências}

Castro, B. (2013). Os gargalos para o ingresso e a permanência das mulheres no mercado de TI no brasil. In XII Conferencia Regional sobre la Mujer de la America Latina y Caribe.

INEP (2015). Exame Nacional de Desempenho de Estudantes - ENADE. Instituto Nacional de Estudos e Pesquisas Educacionais Anísio Teixeira. Disponível em: http://inep.gov.br/enade. Acesso em: 5 fev. 2019.

Maia, M. M. (2016). Limites de gênero e presença feminina nos cursos superiores brasileiros do campo da computação. Cadernos Pagu, (46):223-244.

Moreira, J. A., de Oliveira Mattos, G., and Reis, L. (2014). Um panorama da presença feminina na ciência da computação. Encontro Internacional da Rede Feminista Norte e Nordeste de Estudos e Pesquisa sobre a Mulher e Relações de Gênero.

Nunes, D. J. (2017). Educação superior em computação, estatísticas 2017. Sociedade Brasileira de Computação-SBC. Disponível em: http://www.sbc.org.br/documentosda-sbc/summary/133-estatisticas/1200-pdf-png-educacao-superior-em-computacaoestatisticas-2017. Acesso em: 5 fev. 2019.

Oliveira, A. C., Moro, M. M., and Prates, R. O. (2014). Perfil feminino em computação: Análise inicial. In XXXIV Congresso da Sociedade Brasileira da Computação-CSBC.

Oliveira dos Santos, W. (2017). Mulheres na computação: Uma análise da participação feminina nos cursos de licenciatura em computação. In VI Congresso Brasileiro de Informática na Educação-CBIE.

Rezende, J. M. d. (2009). À sombra do plátano: crônicas de história da medicina. SciELO-Editora Fap-Unifesp.

Rossiter, M. W. (1993). The Matthew Matilda effect in science. Social studies of science, 23(2):325-341. 